\title{
Effect of Addition of Cobalt or Nickel on the Strain Gauge Factor and Electrical Properties of Iron-Chromium Alloys*
}

\author{
By Hakaru Masumoto** and Naoji Nakamura**
}

\begin{abstract}
The present investigators already measured the strain gauge factor $K$ and electrical properties for the wires of $\mathrm{Fe}-\mathrm{Cr}$ alloys containing less than $50 \%$ chromium, and obtained the largest value of 6.2 in $K$ for the alloy containing $20 \%$ chromium. So they have further investigated the influence of the addition of less than $70 \%$ cobalt or $65 \%$ nickel on their properties. Although $K$ of $\mathrm{Fe}-\mathrm{Cr}$ alloys shows some decrease with increasing cobalt or nickel content, the electrical resistivity $\rho$ increases considerably, while the mean temperature coefficient of electrical resistivity $C_{f}$ and the mean thermo-electromotive force relative to copper $E_{m_{f}}$ decrease and reach comparatively small values. The results on $\mathrm{Fe}-15 \% \mathrm{Cr}-35 \% \mathrm{Co}$ and $\mathrm{Fe}-10 \% \mathrm{Cr}-20 \% \mathrm{Ni}$ alloys show that $K$ is 3.9 and $3.7, \rho$ is 88.6 and $86.0 \mu \Omega-\mathrm{cm}, C_{f}$ is $2.6 \times 10^{-4}$ and $3.0 \times 10^{-4}$, and $E_{m_{f}}$ is -0.1 and $-4.7 \mu \nabla /{ }^{\circ} \mathrm{C}$, respectively.
\end{abstract}

(Received November 11, 1968)

\section{Introduction}

In the preceding study ${ }^{(1)}$ the present authors measured the strain gauge factor, $K$, at room temperature for wire specimens of $\mathrm{Fe}$-Cr alloys containing less than $50 \%$ chromium which had been prepared by cold working of about $98 \%$ reduction. The results of measurements showed a large value of $K$ over a wide composition range of chromium with the highest value of 6.2 at $20 \%$ chromium. However, the temperature coefficient of electrical resistivity, $C_{f}$, and the thermo-electromotive force relative to copper, $E_{m f}$, were measured to be $32.7 \times 10^{-4}$ and $+11.0 \mu \mathrm{V} /{ }^{\circ} \mathrm{C}$, respectively, which were considerably larger than those of the commonly-used strain gauge material.

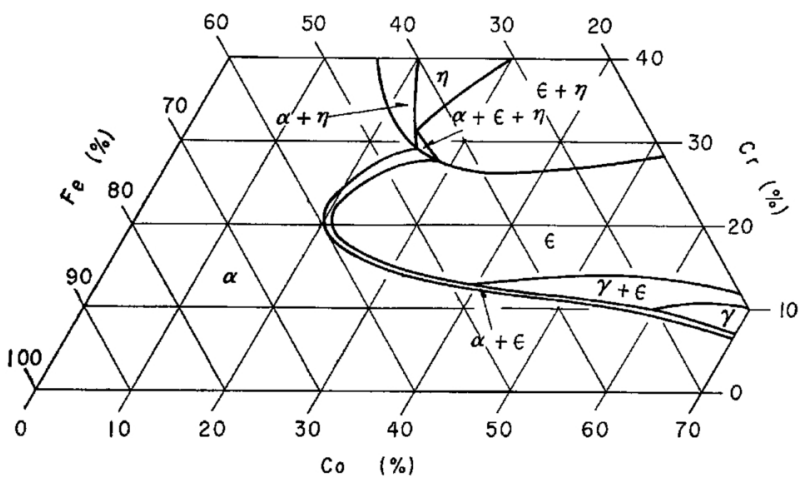

Fig. 1 Equilibrium diagram at $20^{\circ} \mathrm{C}$ of $\mathrm{Fe}-\mathrm{Cr}-\mathrm{Co}$ alloys

\footnotetext{
* This paper was presented at the Autumn Meeting of the Japan Institute of Metals, Oct. 1967, Sapporo, Japan. Published originally in Japanese in Journal of the Japan Institute of Metals, 32 (1968), 852; The 21th report from The Foundation : The Research Institute of Electric and Magnetic Alloys, Sendai, Japan.

** The Foundation : The Research Institute of Electric and Magnetic Alloys, Sendai, Japan.

(1) H. Masumoto and N. Nakamura : J. Japan Inst. Metals, 32 (1968), 681; Trans. JIM, 10 (1969), 124; The 20th Report of The Foundation : The Research Institute of Electric and Magnetic Alloys, Sendai, Japan.
}

Therefore, the present study was intended to examine the effect of the addition of cobalt or nickel as the third element on the strain gauge factor and other properties of $\mathrm{Fe}-\mathrm{Cr}$ alloys. Köster ${ }^{(2)}$ and Wever et al. (3) have studied the phase diagrams on the iron side of $\mathrm{Fe}-\mathrm{Cr}-\mathrm{Co}$ and $\mathrm{Fe}-\mathrm{Cr}-\mathrm{Ni}$ alloys around room temperature, respectively, as shown in Figs. 1 and 2. Fig. 1 shows that the $\mathrm{Fe}-\mathrm{Cr}-\mathrm{Co}$ alloys containing less than $70 \%$ cobalt and $30 \%$ chromium consist largely of the $a$ and $\varepsilon$ phases, but no consideration is given to the $\sigma$ phase. On the other hand, Fig. 2 shows that the $\alpha$ and $\gamma$ phases account for a major composition of the $\mathrm{Fe}-\mathrm{Cr}-\mathrm{Ni}$ alloys containing less than $65 \%$ nickel and $30 \%$ chromium and part of the $\sigma$ phase is revealed in the high chromium composition range.

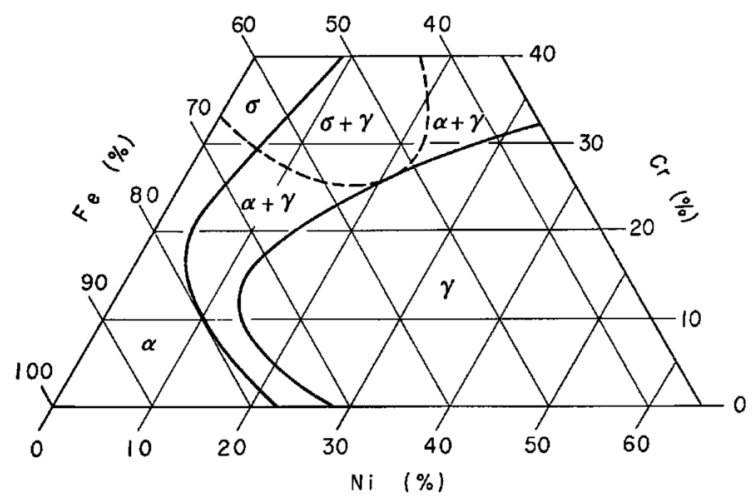

Fig. 2 Equilibrium diagram at $20^{\circ} \mathrm{C}$ of $\mathrm{Fe}-\mathrm{Cr}-\mathrm{Ni}$ alloys

Although these phase diagrams which represent the equilibrium state of the alloys are not directly related to the cold-worked state of the alloys in the present experiment, the diagrams are shown in this paper in view of their significance, as reference data, in carrying out the present experiment.

(2) W. Köster : Arch. Eisenhütt., 6(1932), 113.

(3) F. Wever and W. Jellinghaus : Miteil. Kaiser WilhelmInst. für Eisenforschung, 13 (1931), 93 ; Stainless Iron and Steel (J. H. G. Moneypenny), 2 (1954), 161.

1969 Vol. 10 
Table 1 Results of chemical analysis of metals used

\begin{tabular}{l|l|l|l|l|l|l|l|l|l|}
\hline Metals & $\begin{array}{c}\mathrm{Fe} \\
(\%)\end{array}$ & $\begin{array}{c}\mathrm{Co} \\
(\%)\end{array}$ & $\begin{array}{c}\mathrm{Ni} \\
(\%)\end{array}$ & $\begin{array}{c}\mathrm{C} \\
(\%)\end{array}$ & $\begin{array}{c}\mathrm{S} \\
(\%)\end{array}$ & $\begin{array}{c}\mathrm{Si} \\
(\%)\end{array}$ & $\begin{array}{c}\mathrm{Mn} \\
(\%)\end{array}$ & $\begin{array}{c}\mathrm{Cu} \\
(\%)\end{array}$ & $\begin{array}{c}\mathrm{Pb} \\
(\%)\end{array}$ \\
\hline $\mathrm{Co}(\mathrm{mt})$ & 0.150 & 99.59 & 0.140 & 0.007 & 0.004 & 0.025 & 0.012 & - & - \\
\hline $\mathrm{Ni}(\mathrm{el})$ & 0.0007 & 0.18 & - & - & 0.0002 & 0.0004 & 0.0000 & 0.0005 & 0.0000 \\
\hline
\end{tabular}

\section{Specimens and Experimental Procedures}

The alloying materials, iron and chromium, were of the same kinds as described in the preceding paper ${ }^{(1)}$, but the metallic cobalt and electrolytic nickel used were of the purities shown in Table 1. In the same way as mentioned previously(1), out of the alloying materials totaling $100 \mathrm{~g}$, iron, cobalt or nickel was loaded in an alumina crucible and melted with a highfrequency induction furnace while blowing hydrogen gas on the surface of metals to prevent oxidation. Chromium was then added to the melt and stirred thoroughly for homogenization. In the case of $\mathrm{Fe}-\mathrm{Cr}-$ $\mathrm{Ni}$ alloy's, 0.5\% manganese and 0.3\% silicon were added to the melt so as to increase its workability. The alloy was cast into an iron mold $10 \mathrm{~mm}$ in diameter and $12 \mathrm{~cm}$ in length, and its ingot was forged at about $1000^{\circ} \mathrm{C}$ to a cylindrical rod $5 \mathrm{~mm}$ in diameter. At the intermediate stage of the subsequent cold swaging and drawing, the rod was annealed at $1000^{\circ} \mathrm{C}$ to obtain three kinds of wires with a diameter of $1 \mathrm{~mm}$ (for measurement of $\rho$ ), $0.5 \mathrm{~mm}$ (for measurement of $E_{m f}$ ) and $0.06 \mathrm{~mm}$ (for measurement of $K$ ) in a coldworked state of about $98 \%$ reduction. Finally the pieces $10 \mathrm{~cm}, 1 \mathrm{~m}$ and about $70 \mathrm{~cm}$ in length were cut out from the wires, respectively, and their values in $\rho, C_{f}, E_{m f}$ and $K$ were measured in the same way as described in the preceding paper(1). Since the result of the tensile test provides useful information, the measurement was performed on some of the alloys by the Instron-type testing machine.

\section{Resuilts of Measurements and Consideration}

\section{Strain gauge factor}

Figs. 3 and 4 illustrate the composition dependence of $K$ for the $\mathrm{Fe}-\mathrm{Cr}-\mathrm{Co}$ and $\mathrm{Fe}-\mathrm{Cr}-\mathrm{Ni}$ alloys in a coldworked state of about $98 \%$ reduction, respectively, in which the closed circles represent the specimen compositions. As can be seen from Fig. 3, the value of $K$ for $\mathrm{Fe}-\mathrm{Cr}$ alloys decreases comparatively rapidly at the beginning and then gradually with increasing cobalt addition. The highest value of 6.2 in $K$ for the $\mathrm{Fe}-\mathrm{Cr}$ system with $20 \%$ chromium changes along the $\overline{\mathrm{AB}}$ line of $\mathrm{Fe}: \mathrm{Cr}=4: 1$ with the cobalt content and becomes about 3.0 at $65 \%$ cobalt. It can be understood that the $\overline{\mathrm{AB}}$ line coincides roughly with the critical solution line of the $a$ phase in the equilibrium

(4) M. Yamamoto, T. Nakamichi, N. Yokoyama and N. Hayashi : J. Japan Inst. Metals, 31(1967), 696; M. Yamamoto, T. Nakamichi and N. Yokoyama : J. Japan Inst. Metals, 31 (1967), 702; Sci. Rep., RITU, (50th Anniversary vol.), A18, Suppl. (1966), 486.

(5) R. Bertodo : Proc. Instn. Mech. Engrs., 173 (1959), 605; 178 (1964), 907. phase diagram over the composition range of more than about $30 \%$ cobalt.

As shown in Fig. 4, the value of $K$ for Fe-Cr alloys generally decreases rapidly with increasing nickel content. In this case, the highest value of 6.2 in $K$ for the $\mathrm{Fe}-\mathrm{Cr}$ system decreases to a minimum in the vicinity of the $\alpha+\gamma$ phase, followed by a slight increase up to the composition range of about $13 \%$

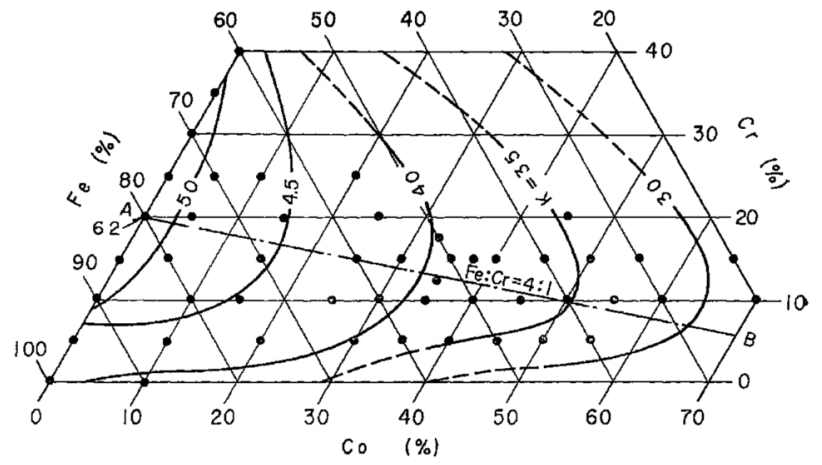

Fig. 3 Strain gauge factor at room temperature of $\mathrm{Fe}-$ Cr-Co alloys in a cold-worked state of about $98 \%$ reduction

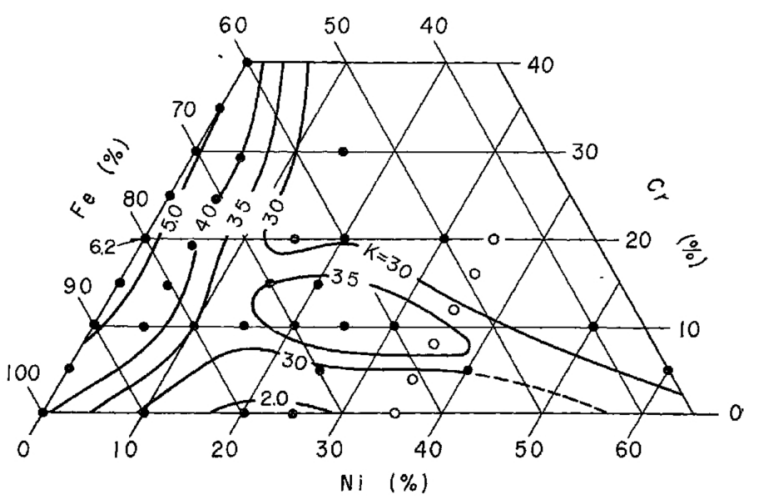

Fig. 4 Strain gauge factor at room temperature of $\mathrm{Fe}-\mathrm{Cr}-$ $\mathrm{Ni}$ alloys in a cold-worked state of about $98 \%$ reảuction

- present investigators ○ Yamamoto et al. (4)

chromium and $20 \%$ nickel in the $\gamma$ phase range, and then decreases linearly. The open circles shown in Fig. 4 represent the compositions of $\mathrm{Fe}-\mathrm{Cr}-\mathrm{Ni}$ alloys measured by Yamamoto et al. (4) under the same condition as used by the present authors. The results in both cases are in good agreement with each other. The results of measurements by Bertodo ${ }^{(5)}$ do not agree with those of the present authors because the specimens of the former contained a large quantity of impurities and were in an annealed state.

\section{Electrical resistivity and its temperature coefficient}

The values in $\rho$ at $20^{\circ} \mathrm{C}$ and in $C_{f}$ at $0^{\circ} \sim 40^{\circ} \mathrm{C}$ for 
$\mathrm{Fe}-\mathrm{Cr}-\mathrm{Co}$ and $\mathrm{Fe}-\mathrm{Cr}-\mathrm{Ni}$ alloys were measured, the results of which are shown in Figs. 5 and 6, respectively. As can be seen from Fig. 5, $\rho$ of iron increases drastically at the beginning and then slowly with increasing chromium and cobalt contents and attains a value greater than $90 \mu \Omega$-cm in the composition range of more than about $23 \%$ cobalt and about 17\% chromium. As shown in Fig. 6, the addition of chromium and nickel increases substantially the $\rho$ value of iron in the $a$ phase range, while in the other phases the amount of the increase slows down and the value reaches a value greater than $90 \mu \Omega-\mathrm{cm}$ as in the case with $\mathrm{Fe}-\mathrm{Cr}-\mathrm{Co}$ alloys. The open circles in the

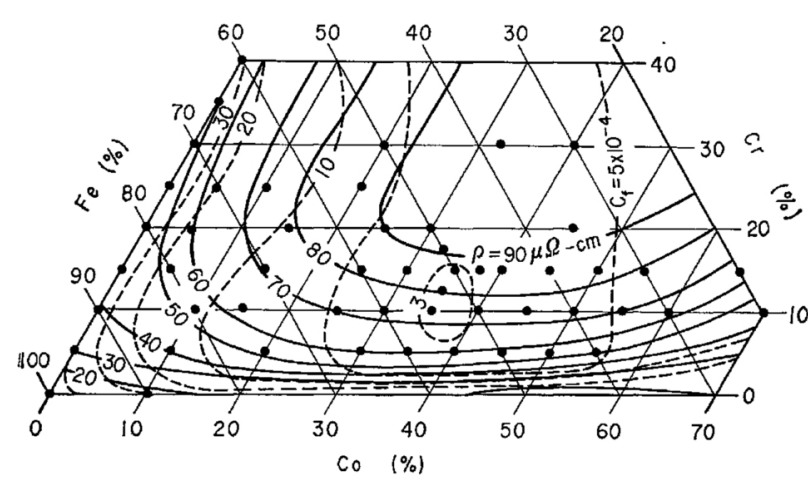

Fig. 5 Electrical resistivity at $20^{\circ} \mathrm{C}$ and its mean temperature coefficient in the temperature range $0^{\circ}$ to $40^{\circ} \mathrm{C}$ for $\mathrm{Fe}-\mathrm{Cr}$-Co alloys in a cold-worked state of about 98\% reduction

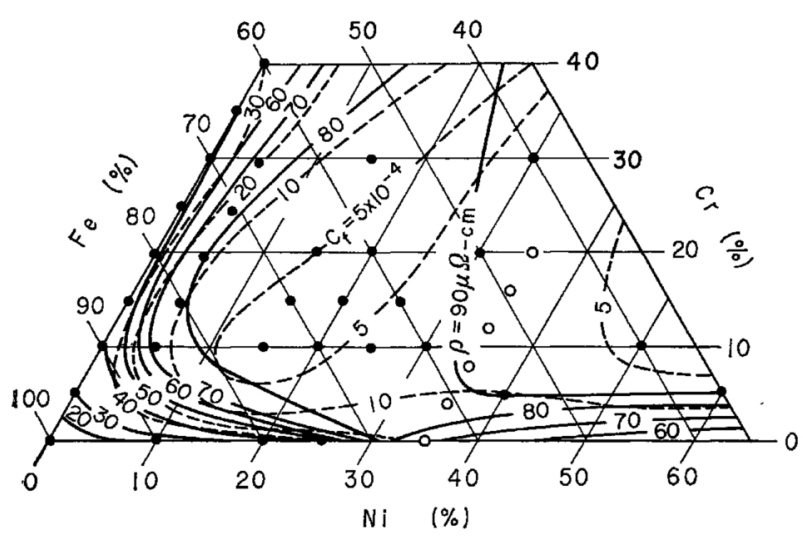

Fig. 6 Electrical resistivity at $20^{\circ} \mathrm{C}$ and its mean temperature coefficient in the temperature range $0^{\circ}$ to $40^{\circ} \mathrm{C}$ for $\mathrm{Fe}-\mathrm{Cr}-\mathrm{Ni}$ alloys in a cold-worked state of about 98\% reduction

- present investigators $\circ$ Yamamoto et al. ${ }^{(4)}$

figure indicate the specimens compositions measured by Yamamoto et al. ${ }^{(4)}$ under the same condition as used by the present authors, and their measured values are in good agreement. For $C_{f}$ of $\mathrm{Fe}-\mathrm{Cr}-\mathrm{Co}$ alloys, the values on the $\mathrm{Fe}-\mathrm{Cr}$ and $\mathrm{Fe}-\mathrm{Co}$ sides decrease rapidly at the beginning and then slowly with increasing cobalt or chromium content, as shown in Fig. 5. The minimum values of $C_{f}$ are shown in the composition range of about $7 \sim 16 \%$ chromium and about $33 \sim 40 \%$ cobalt. As shown in Fig. 6 , the value of $C_{f}$ of $\mathrm{Fe}-\mathrm{Cr}-\mathrm{Ni}$ alloys increases rapidly in the $\alpha$ phase range but decreases gradually in the other phase ranges with increasing chromium or nickel content.

\section{Thermo-electromotive force relative to copper}

Figs. 7 and 8 show the values of $E_{m f}$ at $0^{\circ} \sim 40^{\circ} \mathrm{C}$ for $\mathrm{Fe}-\mathrm{Cr}-\mathrm{Co}$ alloys and $\mathrm{Fe}-\mathrm{Cr}-\mathrm{Ni}$ alloys, respectively. As can be seen from Fig. 7, the positive value of $E_{m f}$ decreases monotonously with the addition of cobalt to $\mathrm{Fe}-\mathrm{Cr}$ alloys and becomes nil at a certain composition between $30 \sim 40 \%$ cobalt, after which the value becomes negative and its absolute value increases gradually. In the case of $\mathrm{Fe}-\mathrm{Cr}-\mathrm{Ni}$ alloys, as shown in Fig. 8, the positive value of $E_{m f}$ of $\mathrm{Fe}-\mathrm{Cr}$ alloys decreases abruptly with the addition of nickel and

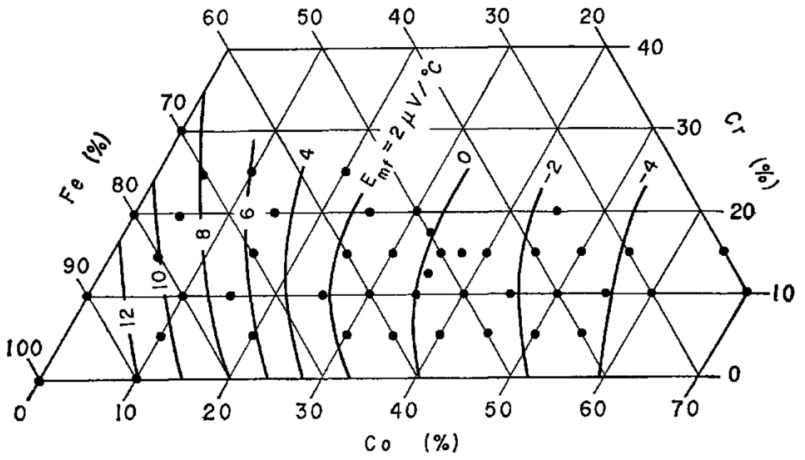

Fig. 7 Mean thermo-electromotive force relative to copper in the temperature range $0^{\circ}$ to $40^{\circ} \mathrm{C}$ for $\mathrm{Fe}-\mathrm{Cr}-\mathrm{Co}$ alloys in a cold-worked state of about $98 \%$ reduction

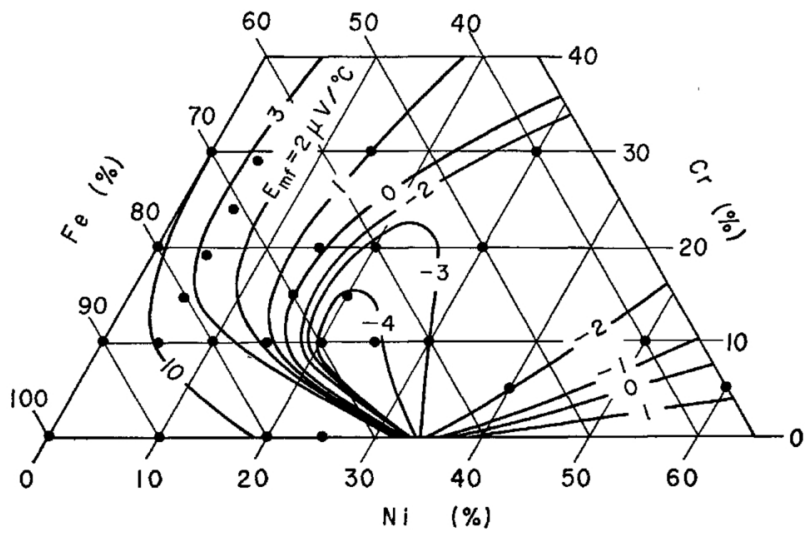

Fig. 8 Mean thermo-electromotive forcs relative to copper in the temperature range $0^{\circ}$ to $40^{\circ} \mathrm{C}$ for $\mathrm{Fe}-\mathrm{Cr}-\mathrm{Ni}$ alloys in a cold-worked state of about $98 \%$ reduction

becomes nil at a composition near the critical solid solution curve of the $\gamma$ phase. After entering the $\gamma$ phase, the value followed a complicated change ranging from about $-4 \mu \mathrm{V} /{ }^{\circ} \mathrm{C}$ to about $+1 \mu \mathrm{V} /{ }^{\circ} \mathrm{C}$.

Based on the above results, the composition dependence of strain gange characteristics was obtained with $\mathrm{Fe}-\mathrm{Cr}-\mathrm{Co}$ alloys containing $15 \%$ chromi$\mathrm{um}$ and $\mathrm{Fe}-\mathrm{Cr}-\mathrm{Ni}$ alloys containing $10 \%$ chromium, respectively. The results are shown in Figs. 9 and 10. As is evident from these figures, the alloys composed of $50 \%$ iron, $15 \%$ chromium and $35 \%$ cobalt and of $70 \%$ iron, $10 \%$ chromium and $20 \%$ nickel are 3.9 and 3.7 in $K, 88.6$ and $86.0 \mu \Omega$-cm in $\rho, 2.6 \times 10^{-4}$ and $3.0 \times$ $10^{-4}$ in $C_{f}$ and -0.1 and $-4.7 \mu \mathrm{V} /{ }^{\circ} \mathrm{C}$ in $E_{m f}$, respectively. This indicates that these alloys show the decrease in $K$ as compared with $\mathrm{Fe}-\mathrm{Cr}$ alloys, but the other 
properties are greatly improved.

Fig. 11 shows the relationship between the changes in electrical resistivity and length at room temperature for wire specimens of the $50 \% \mathrm{Fe}-15 \% \mathrm{Cr}-35 \% \mathrm{Co}$ and $70 \% \mathrm{Fe}-10 \% \mathrm{Cr}-20 \% \mathrm{Ni}$ alloys in a cold-worked state of about $98 \%$ reduction. The linear portion of the resistance vs. length curve accounts for about 0.9 $\%$ in the length change in the former alloy and about $0.65 \%$ in the latter, which are much larger than the linear limit of $0.3 \sim 0.5$ obtained on $\mathrm{Fe}-\mathrm{Cr}$ binary alloy's. Since a large tensile strength is required for alloy wires used in the strain gauge, the tensile test was performed on the wires of the above-mentioned

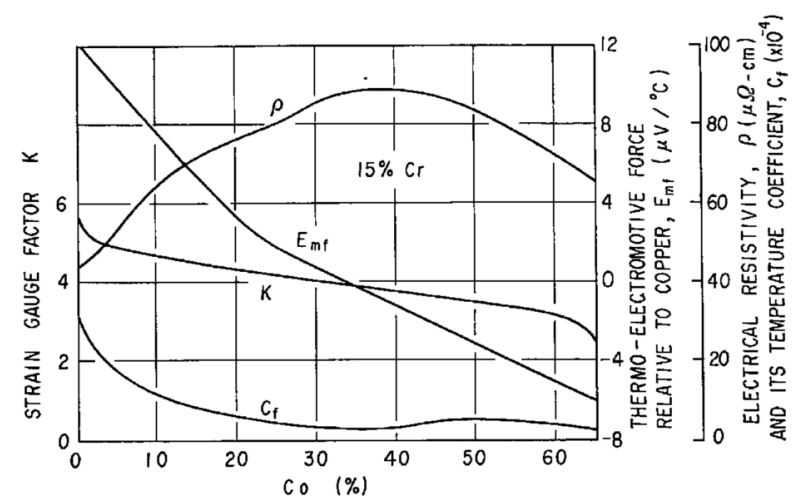

Fig. 9 Strain gauge characteristics of $\mathrm{Fe}-\mathrm{Cr}-\mathrm{Co}$ alloys containing $15 \%$ chromium

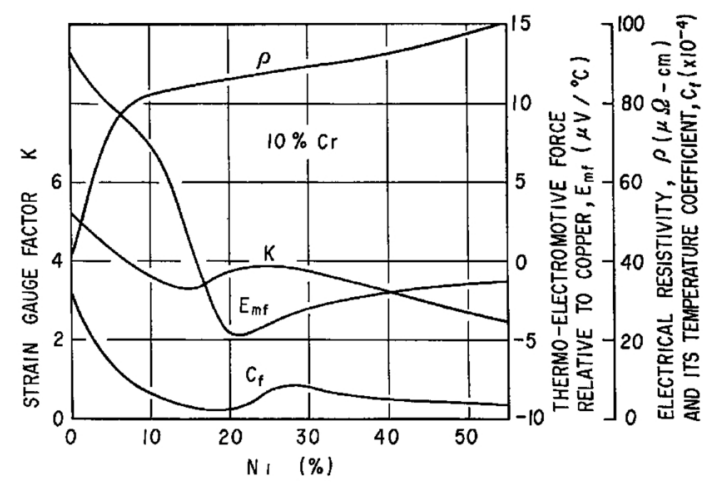

Fig. 10 Strain gauge characteristics of $\mathrm{Fe}-\mathrm{Cr}-\mathrm{Ni}$ alloys containing $10 \%$ chromium

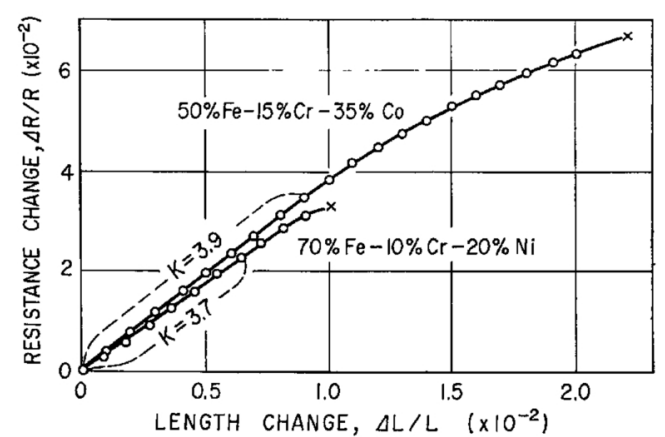

Fig. 11 Relation between changes of resistance and length at room temperature for $\mathrm{Fe}-15 \% \mathrm{Cr}-35 \% \mathrm{Co}$ and $\mathrm{Fe}-10 \% \mathrm{Cr}-20 \% \mathrm{Ni}$ alloys in a cold-worked state of about $98 \%$ reduction two alloys ( $1 \mathrm{~mm}$ in diameter and about $10 \mathrm{~cm}$ in length) and the values obtained were as large as 160 and $130 \mathrm{~kg} / \mathrm{mm}^{2}$, respectively. They were also found to have good workability. Therefore, it seems possible to put these alloys to practical use for various purposes.

\section{Conclusions}

Strain gauge characteristics were measured of FeCr-Co alloys containing less than 30\% chromium and $70 \%$ cobalt and $\mathrm{Fe}-\mathrm{Cr}-\mathrm{Ni}$ alloys containing less than $30 \%$ chromium and $65 \%$ nickel after cold-working of about $98 \%$ reduction. The results obtained are as follows:

(1) The value of $K$ for $\mathrm{Fe}-\mathrm{Cr}$ alloys decreases rapidly at the beginning and then slowly with the addition of cobalt. The highest value of 6.2 in $K$ for the Fe-Cr system with $20 \%$ chromium changes along a line with $\mathrm{Fe}: \mathrm{Cr}=4: 1$ with increasing cobalt content and becomes about 3.0 at $65 \%$ cobalt. In the case of the addition of nickel to Fe-Cr alloys, the value of $K$ decreases generally with increasing nickel content. The highest value of 6.2 in $K$ at $20 \%$ chromium in the $\mathrm{Fe}-\mathrm{Cr}$ system decreases to a minimum value at a composition near the $\alpha+\gamma$-phase and then increases slightly up to a composition near $13 \%$ chromium and $20 \%$ nickel in the $\gamma$ phase, after which it decreases again.

(2) With the addition of chromium and cobalt or chromium and nickel to iron, the electrical resistivity increases and attains a value greater than $90 \mu \Omega$-cm, which is much larger than that of Fe-Cr binary alloys.

(3) With the addition of cobalt or nickel to $\mathrm{Fe}-\mathrm{Cr}$ alloys, the temperature coefficient of electrical resistivity decreases to a minimum value and then increases.

(4) With the addition of cobalt or nickel to $\mathrm{Fe}-\mathrm{Cr}$ alloys, the thermo-electromotive force relative to copper decreases to zero value, after which the value changes into a negative sign and then increases in its absolute value.

(5) The characteristics of the alloys consisting of 50 $\% \mathrm{Fe}-15 \% \mathrm{Cr}-35 \% \mathrm{Co}$ and of $70 \% \mathrm{Fe}-10 \% \mathrm{Cr}-20 \% \mathrm{Ni}$ are obtained respectively as follows: 3.9 and 3.7 in the strain gauge factor, 88.6 and $86.0 \mu \Omega-\mathrm{cm}$ in the electrical resistivity, $2.6 \times 10^{-4}$ and $3.0 \times 10^{-4}$ in temperature coefficients of electrical resistivity and -0.1 and $-4.7 \mu \mathrm{V} /{ }^{\circ} \mathrm{C}$ in the thermo-electromotive force relative to copper.

\section{Acknowledgments}

The authors wish to express their gratitude to Prof. H. Saitô, the Research Institute for Iron, Steel and Other Metals, Tohoku University for his valuable advices throughout the present experiment and also to Mr. T. Oizumi, the former staff of their Research Institute and now assistant professor of Iwate Medical College, for his assistance in the various measurements. 